\title{
Necessidades e comportamento informacional: conceituação e modelos
}

\author{
Martha Martínez-Silveira \\ Mestre em ciência da informação. \\ E-mail:mmartinez_silveira@yahoo.com
}

\section{Nanci Oddone}

Doutora em ciência da informação.

E-mail: neoddone@uol.com.br

\section{Resumo}

A necessidade informacional pode ser entendida como uma experiência subjetiva que ocorre na mente de cada indivíduo em determinada circunstância ou como condição objetiva observável quando uma informação específica contribui para atender ao motivo que a gerou. Comportamento informacional, em contrapartida, está relacionado à busca, ao uso e ao manejo de informações e fontes para satisfazer aquelas necessidades. Um dos segmentos mais estudados da ciência da informação, os conceitos de necessidade e de comportamento informacional, é o objeto deste trabalho de revisão da literatura, que se detém na busca informacional como principal manifestação do comportamento perante a necessidade. Apresentam-se modelos clássicos de comportamento informacional e ilustra-se com a aplicação do modelo de Wilson em pesquisa recentemente concluída no âmbito nacional.

\section{Palavras-chave}

Necessidades informacionais. Comportamento informacional.

Information needs and information behavior: concepts and models

\section{Summary}

An information need can be understood as a subjective experience that takes place in the mind of each individual in certain circumstances or as an objective condition that can be observed when a specific information contributes to answer the need that generated it. Information behavior, on the other hand, is related to the search, use and handling of information sources to satisfy that need. Focusing mainly on the information seeking activity, the present literature review covers the concepts of information needs and information behavior, two of the best studied subjects in Information Science. Classic models are presented and illustrated by describing the application of Wilson's model in a Brazilian recently finished research.

\section{Keywords}

Information needs. Information behavior.

\section{INTRODUÇÃO}

Ao longo dos últimos 50 anos, tem-se testemunhado transformações radicais na sociedade humana. Acompanhando esse processo, a ciência da informação, tradicionalmente envolvida com temas relativos aos usuários e aos usos da informação, desenvolveu, até a década de 1980, estudos centrados nos sistemas de informação e em sua eficiência. Sua maior preocupação era o perfeito funcionamento desses sistemas e de seus mecanismos de recuperação da informação.

Da década de 80 em diante, ao contrário, o aparecimento de recursos voltados para a automação das tarefas documentárias e a mudança na maneira de perceber o usuário, agora na perspectiva de sua interação com as máquinas, despertaram reflexões e interpretações absolutamente diferentes. Enquanto principal beneficiário desses sistemas, percebeu-se que o usuário deveria ocupar o centro das atenções. Foi então que começaram a surgir pesquisas dedicadas especificamente ao exame daqueles que eram de fato os atores centrais de qualquer sistema de informação: não mais os aparelhos ou os artefatos, mas os usuários (FIGUEIREDO, 1994).

Desde os primeiros anos do século XXI, contudo, um novo paradigma vem-se firmando, relacionado a uma perspectiva agora mais socializante. Isto ocorreu porque se percebeu que tanto os sistemas quanto os usuários estão inseridos em contextos históricos e sociais que influem de modo decisivo na definição de suas características. Hoje, observa-se que a perspectiva de estudo é a de que este contexto desempenha papel tão importante quanto as estruturas cognitivas individuais ou as características mecânicas e operacionais dos sistemas de informação.

Vistos em geral como seres pensantes, porém definitivamente ancorados em um contexto concreto de ação e influenciados - mas também limitados - por ferramentas cada vez mais poderosas, os usuários dos sistemas de informação têm um papel central nas preocupações contemporâneas da ciência da informação. Definindo o uso eficiente da informação em diferentes contextos, a identificação das necessidades e do comportamento informacional tanto dos indivíduos quanto dos grupos ocupa hoje um lugar de destaque 
nas pesquisas da área. É com o intuito de aprofundar o conhecimento sobre o tema das necessidades e do comportamento informacional que se apresenta esta revisão de literatura.

\section{NECESSIDADES INFORMACIONAIS}

O conceito de necessidade informacional definido por Wilson em 1981 descreve uma experiência subjetiva que ocorre apenas na mente de cada indivíduo, não sendo, portanto, diretamente acessível ao observador. A necessidade só pode ser descoberta por dedução, através do comportamento, ou por um ato de enunciação da pessoa que a detém. Esse caráter subjetivo já estava evidente na definição formulada por Burnkrant em 1976, na qual o autor afirmava que a necessidade informacional era a representação cognitiva da futura conquista de um desejo. A mesma natureza subjetiva podia ser encontrada na categorização proposta por Morgan e King em 1971 (apud WILSON, 1997), na qual os autores argumentavam que as necessidades emergem a partir de três tipos de motivos: (a) fisiológicos (fome ou sede, por exemplo); (b) desconhecimento (incluindo curiosidade e estímulo sensorial); (c) sociais (desejo de aprovação, status etc.).

Wilson tipifica as necessidades em cognitivas, afetivas e fisiológicas e assinala que, no caso das necessidades informacionais, existem também "motivos" na origem dos comportamentos informacionais: "por qualquer razão a necessidade de informação deve ter um motivo que ocasiona esse comportamento [information behavior]" (WILSON, 1981, p. 6). Ainda nesta linha, Cooper afirma que a necessidade informacional é um estado psicológico:

uma necessidade informacional é algo não observável diretamente. Não podemos, por exemplo, ver suas 'estruturas', no entanto a necessidade informacional existe, pelo menos, na mente do usuário (COOPER, 1971, p. 22).

Apontando também para o caráter cognitivo e não observável das necessidades informacionais, os estudos de Dervin (1992) referem-se à existência de certas lacunas que provocariam descontinuidade no conhecimento humano, que, uma vez percebidas pelo indivíduo, suscitariam o aparecimento da necessidade informacional.

Opondo-se a esse caráter subjetivo da necessidade informacional, Derr analisou o conceito sob outro ângulo. Ele afirmou que a necessidade informacional não é um estado psicológico, e sim uma condição objetiva.:
"É a relação que existe entre a informação e a finalidade dessa informação para o indivíduo" (DERR, 1983, p. 276). Para este autor, portanto, a necessidade informacional residiria na condição observável de que determinada informação contribuiu para atender ao propósito ou o motivo que a gerou. Derr examinou o conceito em diversas etapas, começando por afirmar que a falta de informação não significa, forçosamente, uma necessidade de informação. O desejo de ter uma informação também não é razão suficiente para dizer que há necessidade de informação, assim como o fato de possuir a informação não elimina a necessidade da mesma. As duas condições que devem estar presentes para que se possa dizer que há necessidade de informação são (a) presença de um "propósito" para a informação e (b) que a informação em questão contribua para alcançar este propósito (DERR, 1983).

Além disso, no entendimento de Derr (1983) a questão da necessidade informacional envolveria certos julgamentos. Avalia-se se há um propósito legítimo e se a informação em questão contribui para alcançar este propósito. Afirmar que determinada pessoa possui um propósito para desejar uma informação implica uma avaliação sobre a legitimidade de tal propósito, assim como supor que uma informação serve ou não a determinado propósito constitui uma avaliação sobre a pertinência daquela informação. A validade de tais ponderações dependeria então de dois fatores: (a) da profundidade do raciocínio que levou à conclusão de que determinado propósito é aceitável; (b) da disponibilidade de evidência científica sobre a real contribuição de determinada informação para a satisfação daquele propósito. A necessidade informacional seria então a condição na qual certa informação contribui para atender a um propósito de informação genuíno ou legítimo (DERR, 1983).

As dificuldades de interpretação das afirmações de Derr são muitas. Com efeito, como definir quando um propósito é genuíno ou legítimo e em que grau uma informação pode contribuir para atender a qualquer propósito? Para cada informação podem existir inúmeros propósitos, e são inúmeras as formas em que cada informação pode contribuir para a satisfação de um propósito. $\mathrm{O}$ profissional da informação teria como determinar a validade dos propósitos? Poderia identificar qual informação efetivamente contribui para responder a um propósito?

Em contrapartida, a crítica de Derr à formulação de Wilson envolve uma objeção palpável: se a necessidade informacional só é percebida quando expressa pelo indivíduo, então qual o objetivo de estudá-la como 
experiência subjetiva? Bastaria examinar os desejos dos usuários manifestos nas perguntas. Assim, a unidade de análise poderia ser a pergunta: o usuário formula a pergunta, o profissional da informação monta uma estratégia de pesquisa para recuperar documentos que respondam a esta pergunta e os sistemas de informação são avaliados quanto ao atendimento ou não dessas perguntas. Por essa ótica, o que desencadearia um processo de transferência de informação não seria nem a necessidade nem o desejo de uma informação, mas a formulação de uma pergunta. E ainda haveria outros aspectos a considerar: o usuário nem sempre percebe qual é a informação de que necessita (TAYLOR, 1968) e algumas vezes possui necessidades não-reconhecidas (WILLIAMSON et al., 1989; FORSETLUND; BJORNDAL, 2001).

Em síntese, ao menos dois dos elementos que integram os diferentes conceitos de necessidade informacional podem ser identificados com segurança. $O$ primeiro deles é que há sempre implícito um motivo ou propósito. O segundo é sua natureza de processo cognitivo, que diferenciaria as necessidades informacionais das fisiológicas, por exemplo.

\section{CARACTERÍSTICAS DAS NECESSIDADES INFORMACIONAIS}

As necessidades informacionais geralmente se originam de situações relacionadas às atividades profissionais de cada indivíduo. Mas estas necessidades não são constantes, podem ser influenciadas por vários fatores. Algumas das variáveis que determinam ou dimensionam a necessidade de informação são, por exemplo, (a) as relacionadas com fatores demográficos - idade, profissão, especialização, estágio na carreira, localização geográfica; (b) as relacionadas com o contexto - situação de necessidade específica, premência interna ou externa; (c) as relacionadas com a freqüência - necessidade recorrente ou nova; (d) as relacionadas com a capacidade de prevê-la - necessidade antecipada ou inesperada; (e) as relacionadas com a importância grau de urgência; (f) as relacionadas com a complexidade - de fácil ou difícil solução (LECKIE; PETTIGREW; SYLVAIN, 1996).

Influenciadas principalmente por fatores pessoais, as necessidades informacionais apresentam características mais gerais quando analisadas por grupos de usuários, uma vez que as particularidades e o contexto de cada grupo podem determinar certo padrão. Em relação à freqüência com que uma necessidade se apresenta, por exemplo, Bresnick (1988) destacou que os advogados possuem necessidades recorrentes, relacionadas a casos prévios atendidos pela própria firma que, se não forem bem organizados e administrados, ocasionam muita perda de tempo. Os advogados lidam com um universo muito grande de informações, que envolve tanto assuntos da área legal quanto outros, relacionados com as particularidades de cada caso. Por esta razão, eles necessitam de informações encontradas não somente em fontes primárias e secundárias de recursos legais, mas também em grande quantidade de outras fontes, como bases de dados que cubram assuntos relacionados ao meio ambiente, por exemplo, à segurança, assuntos técnicos e científicos variados (BRESNICK, 1988).

Osheroff et al. (1991), por sua vez, sugeriram que as necessidades informacionais dos médicos são complexas e variáveis. Há respostas que podem ser obtidas nos prontuários médicos, e há questões que requerem a reunião de uma série de informações, como dados do paciente, dados dos registros do hospital e o próprio conhecimento do médico. Segundo Martínez-Silveira (2005), as características que influenciam as necessidades informacionais dos médicos-residentes estão relacionadas ao fato de estes se encontrarem em um momento crítico de sua formação de especialistas, quando o objetivo da prática profissional é principalmente a aprendizagem. Suas necessidades informacionais estão situadas não somente no nível da informação científica mais atualizada, mas sobretudo no nível da informação já consolidada, incluída no que Mendes (1996) denominou 'informação básica' e Camargo Jr. (2002) considerou como 'conhecimento médico’ (MARTÍNEZ-SILVEIRA, 2005).

No caso dos engenheiros, que trabalham em ampla gama de ambientes, suas necessidades informacionais perfilam-se pela ênfase de sua atividade que, geralmente, é a solução de problemas técnicos. O resultado do seu trabalho tende a ser um produto, um processo ou um serviço, mais do que um novo conhecimento em si. Por isto, os engenheiros necessitam de muito mais informação do que a que eles produzem, e essa informação deve ser precisa, atualizada e segura, mas também original. Assim sendo, os engenheiros confiam mais freqüentemente em informações oriundas de colegas ou de fontes internas de informação do que na literatura publicada ou de origem externa à sua instituição (SHUCHMAN, 1981, apud LECKIE; PETTIGREW; SYLVAIN, 1996). 
Por seu tipo de trabalho, os profissionais de enfermagem necessitam de duas classes de informações: aquelas que auxiliam a tomada de decisões sobre os cuidados com os pacientes e informações sobre assuntos gerais da profissão. Para questões rotineiras, eles recorrem a fontes simples, incluindo consultas interpessoais a colegas, médicos ou outros profissionais de saúde (FRANÇA, 2002). Recorrem também a fontes impressas como o prontuário do paciente, resultados laboratoriais e outros. Devido às características deste grupo, as necessidades informacionais demandadas requerem fontes confiáveis e de fácil acesso (BLYTHE; ROYLE, 1993).

Em realidade, todos esses fatores mencionados se interrelacionam de forma bastante complexa, podendo-se ainda mencionar outros que devem ser levados em conta. Por exemplo, uma necessidade pode ser imprevista, mas não muito importante, não requerendo solução imediata; uma outra necessidade inesperada pode ser de grande importância e de extrema urgência. Assim,

o nível de complexidade, o grau de importância e urgência e a condição de previsibilidade de uma necessidade podem afetar tanto o comportamento quanto a busca desta informação (LECKIE; PETTIGREW; SYLVAIN, 1996).

Em síntese, as necessidades informacionais podem ser de diversos tipos. Weigts et al. (1993), por exemplo, categorizam-nas em: (a) necessidade de informação nova; (b) necessidade de elucidar informações já possuídas; (c) necessidade de confirmar uma informação que já se possui. Levando em conta o componente cognitivo das necessidades informacionais e a importância dada às convicções e aos valores, Wilson acrescenta (a) necessidade de elucidar convicções e valores e (b) necessidade de confirmar convicções e valores (WILSON, 1997).

\section{COMPORTAMENTO INFORMACIONAL}

Comportamento informacional é todo comportamento humano relacionado às fontes e canais de informação, incluindo a busca ativa e passiva de informação e o uso da informação. Isso inclui a comunicação pessoal e presencial, assim como a recepção passiva de informação, como a que é transmitida ao público quando este assiste aos comerciais da televisão sem qualquer intenção específica em relação à informação fornecida (WILSON, 2000).

\section{Busca informacional}

A busca informacional consiste na tentativa intencional de encontrar informação como conseqüência da necessidade de satisfazer um objetivo.
Nesta busca, o indivíduo pode interagir com vários tipos de sistema de informação (WILSON, 2000). O autor sugere ainda que a busca informacional decorre do reconhecimento de alguma necessidade percebida pelo usuário e que este pode procurar tanto em sistemas formais quanto em outras fontes, a exemplo de outras pessoas - o que denomina "troca interpessoal de informação” (WILSON, 1997).

Embora o estudo de um grupo de usuários permita estabelecer certos padrões quanto ao tipo de necessidades informacionais daquele grupo, a busca de informação, no entanto, é influenciada por uma série de outros fatores.

\section{Fatores que influenciam a busca informacional}

Segundo Leckie, Pettigrew e Sylvain (1996), existem dois fatores que influenciam de maneira decisiva a busca informacional:

- Fontes de informação: locais onde são procuradas as informações. A depender do profissional e das características da informação que se busca, essas fontes variam, variando também a ordem em que as fontes são consultadas. As fontes mais comumente referidas são colegas, bibliotecas, livros, artigos e a própria experiência. Essas fontes assumem diversos formatos e podem ser acessadas por diferentes canais, tanto os formais quanto os informais. Há fontes externas e internas, orais e escritas, pessoais e coletivas.

- Conhecimento da informação: o conhecimento direto ou indireto das fontes, do próprio processo de busca e da informação recuperada desempenham importante papel no sucesso da busca. Algumas variáveis que devem ser consideradas neste sentido são familiaridade ou sucesso em buscas anteriores, confiabilidade e utilidade da informação, apresentação, oportunidade, custo, qualidade e acessibilidade da informação.

De acordo com Wilson e Walsh (1996), entretanto, são oito as variáveis que intervêm no processo de busca informacional: (a) pessoais; (b) emocionais; (c) educacionais; (d) demográficas; (e) sociais ou interpessoais; (f) de meio ambiente; (g) econômicas; (h) relativas às fontes (acesso, credibilidade, canais de comunicação).

Tais fatores ficam evidenciados quando se analisam o comportamento e a busca de informação realizada pelo próprio interessado. Este representa, em princípio, um especialista na área em que está procurando informação, 
e essa condição influencia todo o processo. Enquanto intermediário, o papel do profissional da informação neste contexto se reveste de outras características. Devadason e Linga (1996) afirmam que os profissionais da informação não sabem de antemão as necessidades informacionais de seus clientes, nem são especialistas em suas respectivas áreas. Um arquiteto, um médico ou um advogado, por exemplo, sabem de antemão as necessidades de seu cliente. Ao contrário destes, que são especialistas do assunto sobre o qual seu cliente é "ignorante", o profissional da informação tem um cliente que é um especialista em sua própria área.

Realizando uma revisão do processo de busca informacional dos médicos, Gruppen elencou os fatores que influem nessa busca: (a) características do médico; (b) características da prática médica, ou seja, do trabalho ou especialidade; (c) possibilidade de contato com colegas. As características do médico podem ser idade, experiência e nível de especialização. Os médicos mais jovens parecem fazer maior uso da literatura médica que os mais velhos. Mais que os jovens, porém, os mais velhos utilizam mais freqüentemente informações de representantes da indústria farmacêutica e preferem os cursos de educação continuada. Tais diferenças entre médicos jovens e mais velhos, contudo, não parecem estar relacionadas à experiência, e sim ao treinamento, à realidade diferenciada de acesso, assim como à familiaridade com vários tipos de fontes de informação. Esta familiaridade refere-se mais especificamente aos recursos eletrônicos (GRUPPEN, 1990).

As características do trabalho ou especialidade incluem o tamanho da comunidade, o tipo de prática e o ambiente. Em relação aos médicos de família, que empregam com mais freqüência informações fornecidas por representantes da indústria farmacêutica, os especialistas, por exemplo, utilizam mais os periódicos e as discussões com colegas (GRUPPEN, 1990). Os médicos de hospitais ou escolas médicas procuram mais os colegas que os médicos que trabalham sozinhos. Médicos em grandes comunidades recorrem mais aos especialistas da comunidade e aos colegas do que os de pequenas comunidades, que preferem consultar colegas ou especialistas de fora da comunidade. Colegas, especialistas, bibliotecas e periódicos são as fontes preferidas pelos médicos de áreas mais populosas (GRUPPEN, 1990).

Em pesquisa com um grupo de médicos-residentes, Martínez-Silveira (2005) destacou dois fatores que caracterizam e moldam o comportamento informacional do médico. O primeiro é a enorme e crescente quantidade de informação científica publicada e o outro é a impossibilidade de esse profissional buscar, encontrar, selecionar, compreender e integrar esta literatura à sua prática. Esses médicos foram analisados quanto ao seu comportamento perante as necessidades informacionais surgidas durante sua prática de atendimento aos pacientes. A primeira observação neste sentido ocorreu ao perceber-se que, quando surgiu a necessidade de uma informação, eles tenderam a recorrer ao médico preceptor para esclarecer suas dúvidas ou superar sua insegurança. Outra opção comportamental desse grupo é tentar localizar a informação de que precisam em sua coleção particular, composta basicamente de livros. Assim, quando notam certas lacunas no seu conhecimento percebidas tanto como interesse em obter maiores informações sobre a doença como desejo de aprofundar o assunto, em vez de utilizar artigos científicos eletrônicos e recursos mais sofisticados de busca, os médicos-,residentes preferem recorrer a informações mais sedimentadas, como as que se encontram em livros, para preencher a lacuna informacional, entender melhor cada situação e consolidar seus conhecimentos. Estas preferências estão respaldadas na circunstância de que a situação vivida por este tipo de profissionais médicos é ainda uma situação de dependência cognitiva e intelectual em relação a mentores mais experientes, seja por meio dos livros ou dos preceptores.

Nesse sentido, apesar de o contexto ter influência direta no processo de definição do comportamento informacional, o que parece ser determinante na percepção da necessidade, na escolha das fontes de informação e na decisão de efetivamente buscar a informação não é exatamente a disponibilidade dos recursos e sim os processos cognitivos. Assim,

pode-se estar em Salvador ou em Nova Iorque, os recursos, à disposição podem ser inúmeros e sofisticados ou poucos e de difícil manejo, o que faz com que os médicos se mobilizem rumo às fontes é, em primeiro lugar, o motivo que os leva à busca e, em seguida, sua percepção de vir a ter êxito na empreitada com um mínimo de esforço (MARTÍNEZ-SILVEIRA, 2005, p. 143)

\section{MODELOS DE COMPORTAMENTO INFORMACIONAL}

A partir dos anos 1980, os estudos sobre comportamento e necessidades informacionais deixaram de enfatizar os sistemas propriamente ditos e passaram a valorizar a perspectiva do usuário, atribuindo 
mais ênfase ao seu papel na transferência da informação. $\mathrm{Na}$ mesma época, as técnicas qualitativas começaram a substituir as quantitativas para este tipo de pesquisa. Em 1981, Wilson concebeu um modelo de comportamento informacional (figura 1), inspirado nas necessidades fisiológicas, cognitivas e afetivas dos indivíduos. $\mathrm{O}$ contexto dessas necessidades seria configurado pelo próprio indivíduo, pelas demandas de seu papel na sociedade e pelo meio ambiente em que sua vida e seu trabalho se desenrolam. As barreiras que interferem na busca de informação surgiriam deste mesmo contexto (WILSON, 1981).

\section{FIGURA 1}

Modelo de comportamento informacional de Wilson

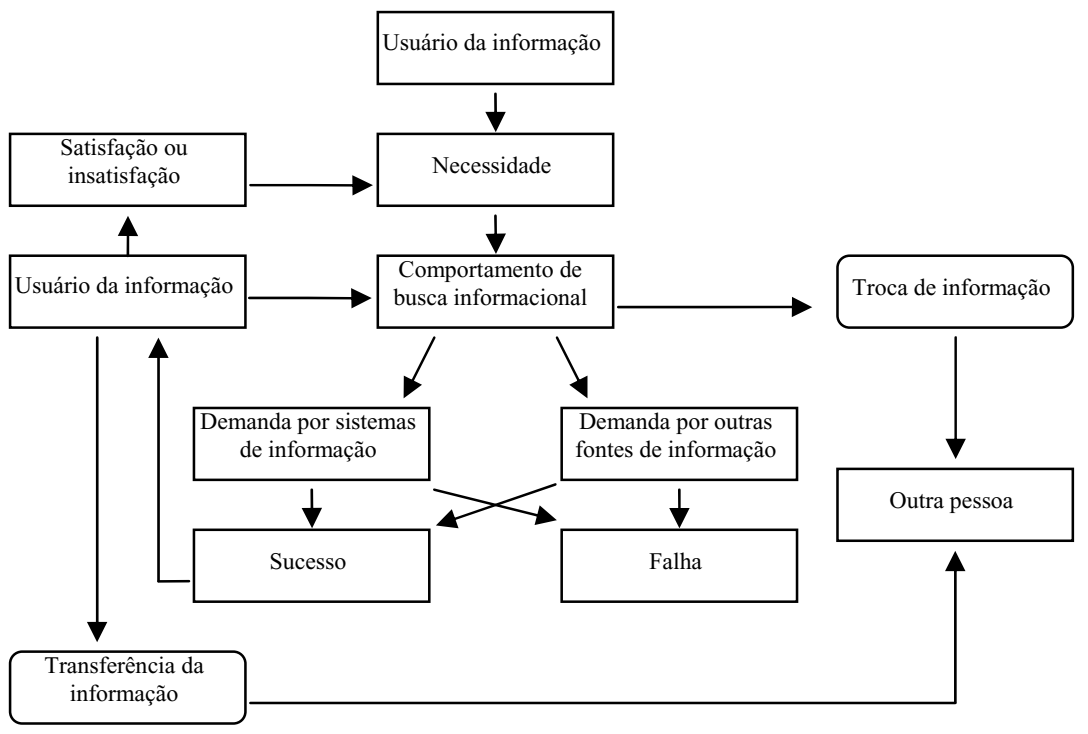

Em 1983, Dervin desenvolveu uma teoria que ficaria conhecida como o modelo do sense-making (figura 2), constituído pelos seguintes elementos: (a) a situação, em tempo e espaço, seria o contexto no qual surge o

\section{FIGURA 2}

\section{Estrutura do modelo do sense-making de Dervin}

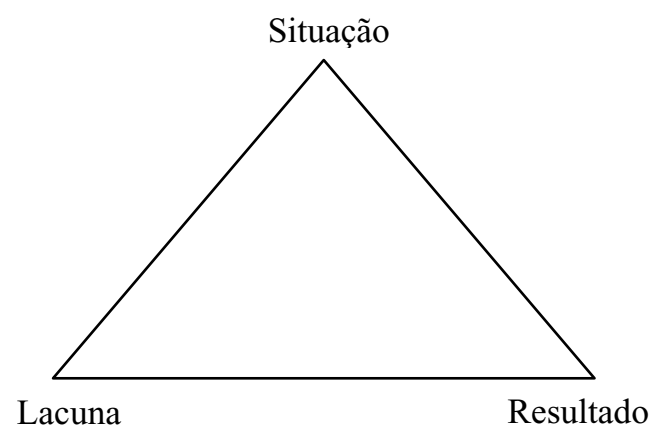

problema informacional; (b) a lacuna (gap), que seria a distância entre a situação contextual e a situação desejada (incerteza); (c) o resultado, que representa a conseqüência do processo de sense-making (DERVIN, 1983).

De natureza cognitiva, não-observável, o modelo de Dervin compreende a necessidade informacional como algo subjetivo, situacional e holístico. Estudando o conceito em contextos específicos, o modelo tenta avaliar como a necessidade emerge, desenvolve-se e é satisfeita. $\mathrm{O}$ usuário não é visto como um receptor passivo. Ele é percebido como sujeito ativo no centro de um processo de mudança (MENDES, 1996).

Para estudar as necessidades informacionais, Dervin empregou uma metáfora do modelo do sensemaking: situação-lacuna-resultado e exemplificou a ponte, que constitui o meio de preencher a lacuna entre a situação e o resultado (figura 3). A autora argumentou que toda necessidade informacional surge da descontinuidade no conhecimento provocada por uma lacuna. Em sua rotina cotidiana, os indivíduos procuram preencher as lacunas informacionais de várias formas, seja estudando, pesquisando ou conversando com outras pessoas. A satisfação das necessidades informacionais funciona como um acréscimo de degraus na experiência adquirida do indivíduo. Cada momento em determinado tempo e espaço é um novo degrau. Os degraus relacionados à definição e ao fechamento da lacuna configuram estratégias cognitivas necessárias à obtenção de respostas, algo bastante difícil de fazer e que depende do indivíduo e da situação. Neste percurso, o indivíduo precisa de esforço para se perceber, perceber o meio ambiente e ir efetuando os ajustes necessários (DERVIN, 1992).

FIGURA 3

Metáfora do modelo do sense-making de Dervin

Ponte

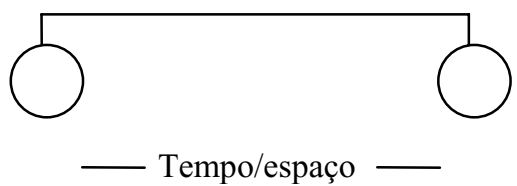

Situação Lacuna Resultado 
A importância do modelo de Dervin se reflete nas análises metodológicas que gerou, trazendo à tona questionamentos que podem revelar a natureza de uma situação problemática, podem indicar até que ponto a informação serve de ponte entre a lacuna e a satisfação, assim como podem definir os resultados do uso da informação (WILSON, 1999).

Em 1989, Ellis elaborou um modelo do comportamento humano na busca informacional (figura 4). Esse modelo não envolvia um diagrama, mas uma série de categorias de atividades de busca informacional: começar (atividades de início da busca); encadear (prosseguir a busca); browsing (busca semidirigida em locais potenciais de busca); diferenciar (filtrar e selecionar); monitorar (continuar revendo as fontes identificadas como essenciais); extrair (trabalhar sistematicamente com as fontes de interesse); verificar (conferir a veracidade das informações) e finalizar (ELLIS, 1989). A importância do modelo de Ellis reside no fato de resultar de pesquisa empírica e de ter sido testado em diversos estudos (WILSON, 1999). "As inter-relações ou interações entre essas categorias em qualquer padrão individual de busca informacional dependerão das circunstâncias específicas da busca em questão naquele momento particular" (ELLIS, 1989, p. 178).

\section{FIGURA 4}

Fases do comportamento na busca informacional de Ellis

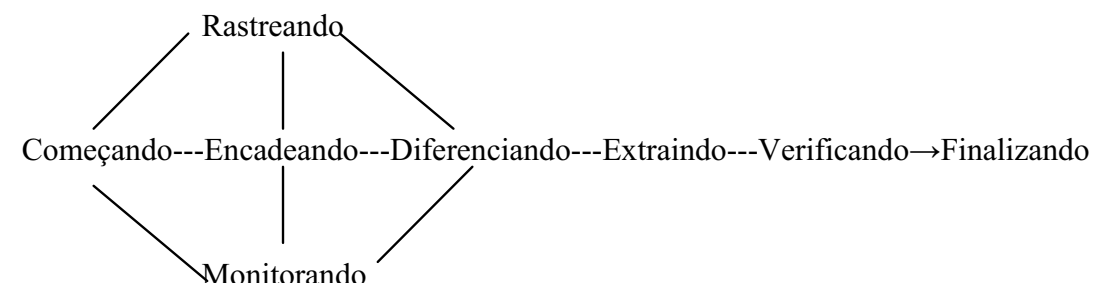

são iniciação, seleção, exploração, formulação, coleta e apresentação. A iniciação, por exemplo, caracterizase por sentimentos de incerteza, idéias vagas sobre o tema. A atitude desta fase é simplesmente reconhecer a necessidade da informação. Outras atitudes pertinentes são identificar, investigar, formular, coletar e completar. $\mathrm{O}$ modelo de Kuhlthau sugere que o estado emocional inicial de incerteza, confusão e ambigüidade associado à necessidade de buscar informação vai sendo substituído por confiança e satisfação à medida que se avança na busca e na hipótese de que o indivíduo está obtendo sucesso.

Em seu modelo de comportamento informacional revisado (figura 4), Wilson e Walsh (1996) propuseram conexões com outros domínios, incluindo psicologia, comunicação em saúde e pesquisa para leigos. Embora como foco da necessidade informacional seu novo modelo tenha mantido a "pessoa em seu contexto", houve necessidade de incluir um estágio entre essa pessoa e sua consciência da necessidade de informação: justamente o ponto chamado por Dervin de "lacuna" entre a situação e o uso da informação (1983, apud DERVIN; NILAN, 1986). Para preencher este espaço Wilson adotou o conceito de "mecanismo de ativação" (activating mechanism), proveniente da teoria do estresse/ enfrentamento (stress/coping theory), que o ajudou a explicar por que algumas necessidades informacionais não se convertem em processos de busca.

Percebendo a existência de outra fase intermediária, agora entre a consciência da necessidade informacional e a atitude requerida para satisfazê-la, Wilson fez então uso de conceitos da teoria do risco/ recompensa (risk/reward theory) para mostrar como e por que o que ele chamou de "variáveis intervenientes" podem desencadear ou obstruir as iniciativas de busca de informação. As fontes, por exemplo, podem tornarse barreiras ao processo de busca: ao investigar por que algumas fontes de informação são mais utilizadas do que outras, verifica-se que, quando há várias alternativas similares a escolher, os esforços de pesquisa são proporcionais às recompensas oferecidas em cada fonte. Outro conceito empregado por Wilson para explicar o funcionamento das "variáveis intervenientes" foi o de "auto-eficácia" (self-efficacy), oriundo da teoria da cognição social (social cognitive theory), que, por sua vez, foi desenvolvida a partir da teoria do estímulo-resposta (stimulus-response theory).
Kuhlthau (1991) acrescentou ao modelo de Ellis uma associação entre sentimentos, pensamentos e atitudes. Contudo, sua perspectiva é fenomenológica, não tanto cognitiva. As fases propostas por Kuhlthau 
A "auto-eficácia" sugere a existência de uma crença segundo a qual qualquer indivíduo sempre pode "produzir o comportamento necessário à obtenção dos resultados [por ele desejados]" (BANDURA, 1977, apud WILSON, 1999, p. 257). Nesse contexto, variáveis pessoais de natureza psicológica ou demográfica, por exemplo, acabam neutralizadas pela força da "auto-eficácia".

Observa-se, portanto, estreita relação entre a "autoeficácia" e as estratégias de enfrentamento, já que a crença na própria eficiência pode afetar o modo como o indivíduo responde a uma situação de necessidade informacional, o tempo que persiste na busca e a dimensão do esforço que vai dedicar a ela. Wilson e Walsh (1996) conjecturam que determinada pessoa, mesmo ciente da utilidade de uma fonte de informação, pode falhar no uso da mesma, se estiver insegura sobre sua capacidade de lidar corretamente com ela. O comportamento descrito no modelo revisado de Wilson e Walsh (figura 5) envolve maior número de elementos que o da "busca ativa". Aqui o "processo de informação e uso" é definido como indispensável à retroalimentação (feedback), para saber se a necessidade de informação foi de fato satisfeita.

Por fim, como forma de ilustrar a aplicação do modelo de Wilson a um grupo específico de usuários, apresenta-se o modelo de comportamento informacional dos médicosresidentes, extraído do estudo empírico conduzido por Martínez-Silveira (2005) (figura 6, a seguir).

\section{FIGURA 5}

\section{Modelo revisado de comportamento informacional de Wilson}

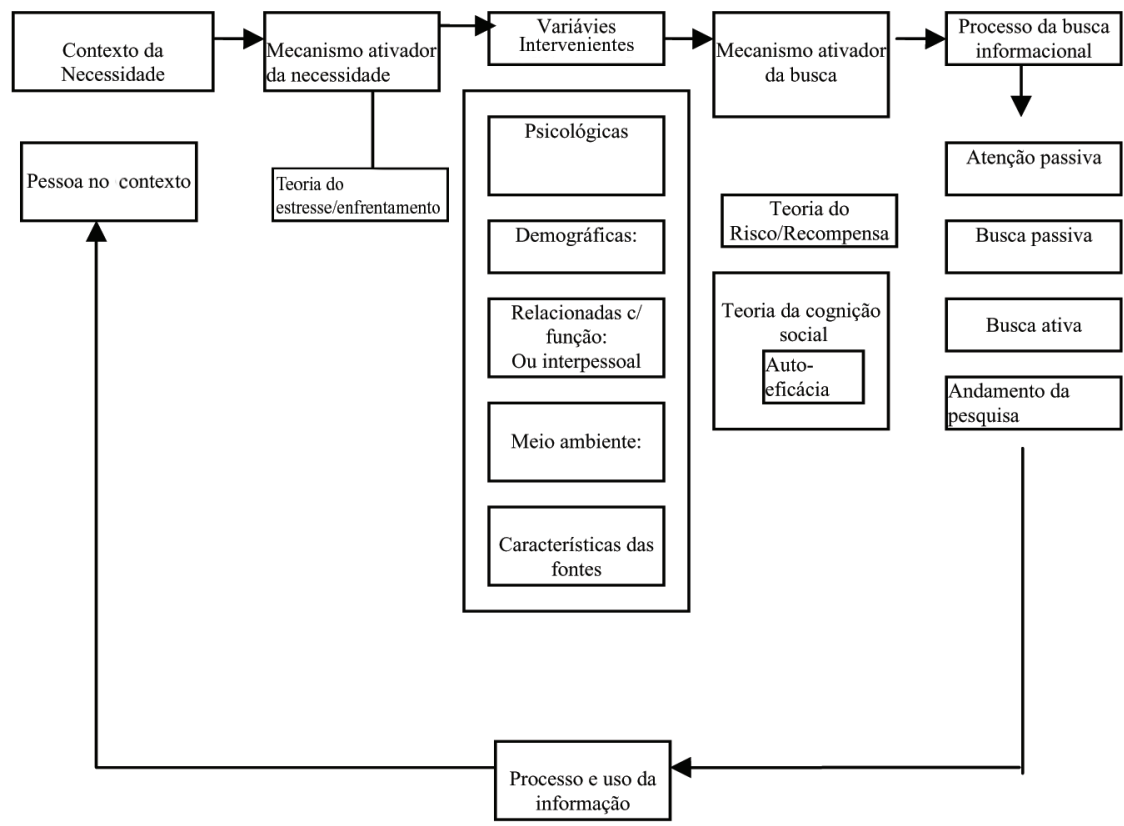

O contexto das necessidades informacionais apresentado neste estudo foi o do atendimento ao paciente, a consulta propriamente dita, na qual a necessidade informacional focalizava assuntos científicos relacionados à saúde do paciente. O mecanismo ativador da necessidade deste grupo estava situado na área cognitiva, ou seja, relacionava-se ao motivo ou à premência de responder a um questionamento, uma carência informacional ou dúvida.

Os motivos apontados pelos médicos-residentes avaliados nesta pesquisa também estavam associados à necessidade de conhecer. Descreviam uma necessidade cognitiva básica, tal como a simples curiosidade: a necessidade de saber e o desejo de estar informado. "Ter de apresentar o caso ao grupo ou ao supervisor" era uma imposição do contexto e representava um motivo forte para desencadear a busca, pois algo era esperado dessa pessoa, ou seja, existia um compromisso de ter de buscar a informação. Como afirma Burnkrant (1976), é apenas uma representação cognitiva de um objetivo futuro que se deseja alcançar. $\mathrm{O}$ que esses médicos-residentes desejavam era desempenhar um bom papel quando tivessem de apresentar o caso perante seus superiores e colegas. Por isso, eles tinham forte motivo para desencadear o processo de busca informacional.

Esta mesma motivação ("ter de apresentar o caso...") pode ser analisada em conjunto com o "interesse especial pelo paciente". Neste caso, ambas as razões representam um tipo de necessidade de aceitação, inserindo-se na categoria "influência social" que, de acordo com Gorman (1995), referese à necessidade de conhecimento para preencher expectativas e convicções dos outros, tanto dos colegas quanto dos familiares e dos próprios pacientes.

As variáveis que intervêm na decisão da busca caracterizaram-se como de origem psicológica (necessidade de conhecer ou simples curiosidade) e demográfica (pessoas relativamente jovens, estudantes; relacionadas com a função), pois os sujeitos da pesquisa eram médicosresidentes, cuja função principal envolve tomar decisões sobre a saúde do paciente. 
O meio ambiente interveniente estava marcado pela falta de boas bibliotecas e de serviços informacionais, assim como pela falta de tempo para dedicar às buscas. As características das fontes também intervinham de forma importante, pois as bases de dados eletrônicas resultavam de difícil manejo, os indivíduos não dominavam a prática de utilização dos recursos e não acreditavam que pudessem encontrar com facilidade as respostas nestas fontes.

\section{REFERÊNCIAS}

BANDURA, A. Self efficacy: towards a unifying theory of behavioural change. Psychological Review, v. 84, n. 2, p. 191-215, 1977.

BLYTHE, J; ROYLE, J. A. Assessing nurses' information needs in the work environment. Bulletin of the Medical Library Association, v. 81, n.4, p. 433-435, 1993.
FIGURA 6

Modelo de comportamento informacional dos médicos-residentes de Martínez-Silveira

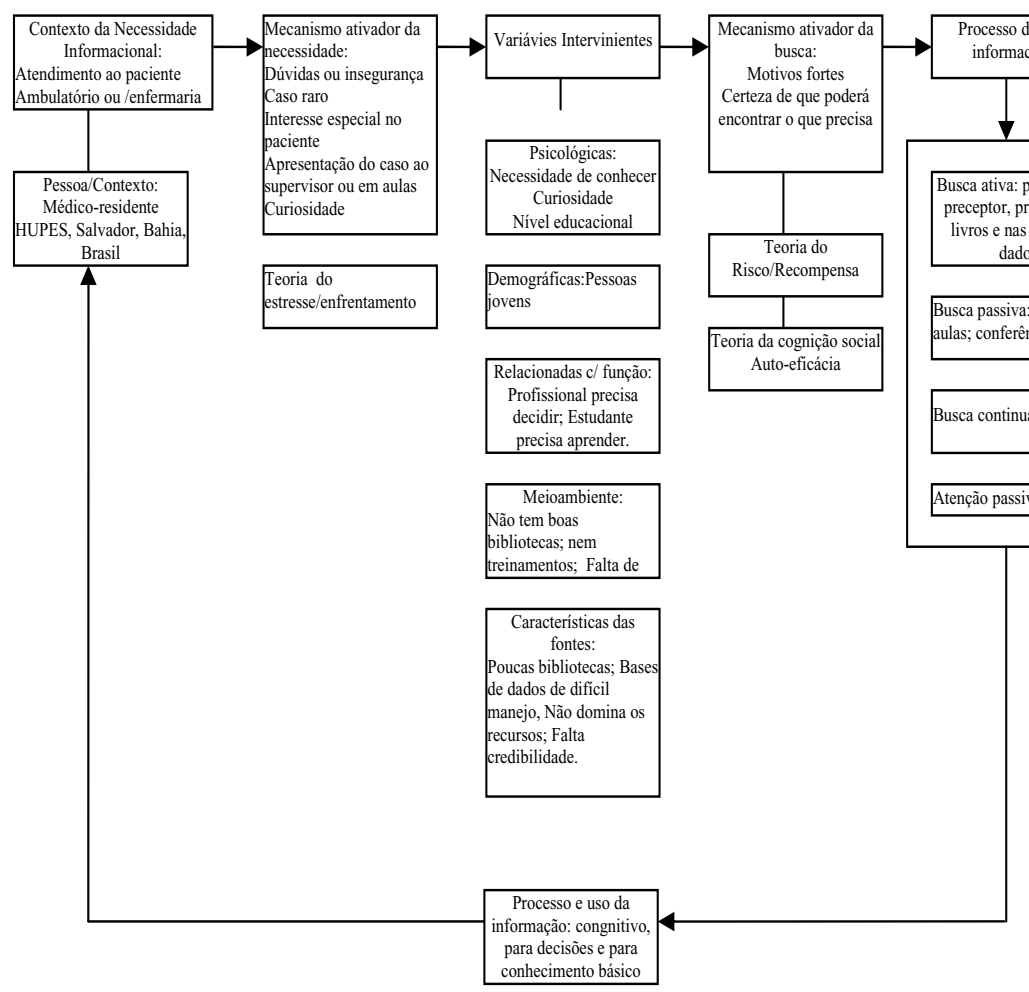

BRESNICK, D. The lawyer as information manager. Legal Studies Forum, v. 12, n. 3, p. 275-284, 1988.

BURNKRANT, R. E. A motivational model of information-processing intensity. Journal of Consumer Research, v. 3, p. 21-30, 1976.

CAMARGO JUNIOR, K. R. The thought style of physicians: strategies for keeping up with medical knowledge. Social Studies of Science, v. 32, n. 5-6, p. 827$855,2002$.

CHOO, C. W.; DETLOR, B.; TURNBULL, D. A behavioral model of information seeking on the Web: preliminary results of a study of how managers and IT specialist use the web. In: ASIS Annual Meeting, 1998. Contributed paper. Disponível em: < http:/ /choo.fis.utoronto.ca/fis/respub/asis98/>. Acesso em: 30 abr. 2005.
O motivo que desencadeia a busca é a certeza de ter êxito na empreitada, e por isso o grupo optava em primeira instância por consultar o médico supervisor e os livros. A busca propriamente dita dava-se então junto aos professores ou preceptores e mediante consulta a livros, geralmente da sua própria coleção. Somente em segunda instância essa população recorria ao computador e, por meio desse equipamento, às bases de dados, internet e periódicos eletrônicos. Este ciclo encerrava-se com a obtenção ou não da informação, caracterizando um processo cognitivo de alteração informacional para a tomada de decisão.

Artigo submetido em 05/06/2006 e aceito em 17/04/2008.
COOPER, W. S. A definition of relevance for information retrieval. Information Storage and Retrieval, v. 7, n. 1, p. 21-29, 1971.

DERR, R. L. A conceptual analysis of information need. Information Processing and Management, v. 19, n. 5, p. 273 278, 1983.

DERVIN, B. An overview of sense-making research: concepts, methods and results to date. International Communications Association Annual Meeting, Dallas, Texas, 1983.

. From the mind's eye of the user?: the sense-making qualitative-quantitative methodology. In: GLAZIER, J. D.; POWELL, R. R. Qualitative research in 
information management. Englewood: Libraries Unlimited, 1992. p. 61-84.

; NILAN, M. Information needs and uses. Annual Review of Information Science and Technology (ARIST), v. 25, p. 3-33, 1986.

12. DEVADASON, F. J.; LINGA, P. P. A methodology for the identification of information needs of users. In: IFLA GENERAL CONFERENCE, 62., 1996. Electronic proceedings... Disponível em: <http:// www.ifla.org/IV/ifla62/62-devf.htm $>$. Acesso em: 03 nov. 2003.

ELLIS, D. A behavioural approach to information retrieval system design. Journal of Documentation, v. 45, n. 3, p. 171-212, 1989.

FIGUEIREDO, N. M. Estudo de uso e usuários da informação. Brasília: Ibict, 1994.

FORSETLUND, L.; BJORNDAL, A. The potential for research-based information in public health: identifying unrecognized information needs. BMC Public Health, v. 1, p. 1-8, 2001. Disponível em: < http:/ /www.biomedcentral.com/1471-2458/1/1>. Acesso em: 15 dez. 2004.

FRANÇA, L. D. O comportamento informacional dos profissionais médicos e enfermeiros do Programa Saúde da Família (PSF) - Sistema Único de Saúde (SUS). 2002. Dissertação (Mestrado em Ciência da Informação) Escola de Ciência da Informação. Universidade Federal de Minas, 2002.

GORMAN, P. N. Information needs of physicians. Journal of the American Society of Information Science, v. 46, n. 10, p. 729-736, 1995.

GRUPPEN, L. D. Physician information seeking: improving relevance through research. Bulletin of the Medical Library Association, v. 78, n. 2, p. 165-172, 1990.

KULTHAU, C. C. Inside the search process: information seeking from the user's perspective, Journal of the American Society for Information Science, v. 42, n. 5, p. 361 371, 1991.

LECKIE, G. J.; PETTIGREW, K. E.; SYLVAIN, C. Modeling the information seeking of professional: a general model derived from research on engineers, health care professionals and lawyers. Library Quarterly, v. 66, n. 2, p. 161-193, 1996.

MARTINEZ-SILVEIRA, M. S. A informação científica na prática médica: estudo do comportamento informacional do médico-residente. 2005. 184 p. Dissertação (Mestrado em Ciência da Informação) Instituto de Ciência da Informação. Universidade Federal da Bahia, Salvador, 2005.

MENDES, H. M. Health information acquisition in british and brazilian hospitals. 1996. 265 p. Tese (Doutorado em Ciência da Informação)- Department of Information Science, Loughborough University, Loughborough, 1996.

OSHEROFF, J. A. et al. Physicians' information needs: analysis of questions posed during clinical teaching. Annals of Internal Medicine, v. 114, n. 7, p. 576-581, 1991.

TAYLOR, R. S. Question-negotiation and information seeking in libraries. College and Research Libraries, v. 29, p. 178-194, 1968.

WEIGTS, W. et al. Patients' information seeking actions and physician' responses in gynecological consultations. Qualitative Health Research, v. 3, n. 4, p. 398-429, 1993.

WILLIAMSON, J. W. et al. Health science information management and continuing education of physicians: a survey of U.S. primary care practitioners and their opinion leaders. Annals of Internal Medicine, v. 110, n. 2, p. 1551-160, 1989.

WILSON, T. D. On user studies and information needs. Journal of Documentation, v. 31, n. 1, p. 3-15, 1981.

. Information behaviour: an interdisciplinary perspective. Information Proceeding and Management, v. 33, n. 4, p. 551-572, 1997.

. Models in information behaviour research. The Journal of documentation, v. 55, n. 3, p. 249-270, 1999.

. Human information behavior. Informing Science, v. 3, n. 2, p. 49-53, 2000.

; WALSH, C. Information behaviour: an inter-disciplinary perspective. British Library Research and Innovation Report, n. 10, 1996. Disponível em: < http:// informationr.net/tdw/publ/infbehav/prelims.html $>$. Acesso em: 16 out. 2003. 